\title{
De Verfall e Verkümmerung a Katastrophe: a modernidade em Walter Benjamin
}

\author{
[From Verfall and Verkümmerung to Katastrophe: modernity in Walter Benjamin] \\ http://dx.doi.org/10.11606/1982-88372546233
}

André Macedo ${ }^{1}$

\begin{abstract}
The aim of this article is to discuss a series of key concepts and notions of Walter Benjamin - in the German edition of his writings - taking as starting point the hypothesis that, in the context of his precept of den Pessimismus organisieren, there is a shift from a focus on modernity as Verfall and Verkümmerung of human capacities towards Katastrophe of humanity and the world. This shift, certainly linked to the historical events that led to the author's death in 1940, begins with discussions on Vermögen and Wahrnehmung and concludes with the theses on Begriff der Geschichte. And between the beginning and the conclusion are reflections pertinent to the approach of "Untergang des Subjekts" (ADORNO 2011: 241) and of Massenproduktion in general and in art: Erfahrung, Phantasievorstellung, Potenz, Erinnern, Gedächtnis, Erzählen, Lyrik and Aura. Therefore, it is necessary to investigate the shift from Verfall and Verkümmerung to Katastrophe through four essays on Sprache, the main writings relevant to Untergang des Subjekts and Massenproduktion (Passagen-Werk, "Der Erzähler", Charles Baudelaire and essays on the work of art and photography) and the theses of "Über den Begriff der Geschichte". Finally, it is worth considering that, throughout this process, Benjamin does not forget dealing with Hilfsmittel for Vertiefung der Apperzeption.
\end{abstract}

Keywords: Walter Benjamin; Modernity; Verfall; Verkümmerung; Katastrophe.

Resumo: O objetivo desse artigo é retomar uma série de conceitos-chave e noções de Walter Benjamin - na edição alemã de seus escritos - a partir da hipótese de que, através de seu preceito de den Pessimismus organisieren, há uma passagem do enfoque da modernidade como Verfall e Verkümmerung de capacidades humanas ao seu enfoque como Katastrophe da humanidade e do mundo. Essa passagem, certamente vinculada aos acontecimentos históricos que levam à morte do autor em 1940, inicia-se com as discussões sobre Vermögen e Wahrnehmung e conclui-se com as teses sobre Begriff der Geschichte. E entre o início e a conclusão estão reflexões pertinentes à abordagem de "Untergang des Subjekts" (ADORNO 2011: 241) e de Massenproduktion em geral e na arte: Erfahrung, Phantasievorstellung, Potenz, Erinnern, Gedächtnis, Erzählen, Lyrik e Aura. Sendo assim, é necessário investigar a passagem de Verfall e Verkümmerung a Katastrophe através de quatro ensaios sobre Sprache, dos principais escritos pertinentes a Untergang des Subjekts e Massenproduktion (Passagen-Werk, "Der Erzähler", Charles Baudelaire e ensaios sobre a obra de arte e a fotografia) e das teses de "Über den Begriff der Geschichte". Cabe, por fim, considerar que, em todo esse processo, Benjamin não deixa de tratar de Hilfsmittel para Vertiefung der Apperzeption.

Palavras-chave: Walter Benjamin; Modernidade; Verfall; Verkümmerung; Katastrophe.

\footnotetext{
${ }^{1}$ Universidade Federal do Pará, Faculdade de Letras, Campus Breves, Av. Afuá II - Breves, PA, 68800000. Brasil. E-mail: andre.macedo@alumni.usp.br. ORCID: 0000-0002-7923-4111
}

(cc) BY-NC

Pandaemonium, São Paulo, v. 25, n. 46, mai.-ąo. 2022, p. 233-249 


\section{Introdução}

O objetivo do artigo é retomar uma série de conceitos-chave e noções de Walter Benjamin diretamente no processo de elaboração em seus próprios escritos reunidos pela edição alemã - a partir da hipótese de que, através de seu preceito de den Pessimismus organisieren, há uma passagem do enfoque da modernidade como Verfall e Verkümmerung de capacidades humanas ao seu enfoque como Katastrophe da humanidade e do mundo - "Trümmer auf Trümmer" (BENJAMIN 1991a: 697). ${ }^{2}$

Essa passagem, certamente vinculada aos acontecimentos históricos que levam à morte do autor em 1940, inicia-se com as discussões sobre Vermögen e Wahrnehmung e conclui-se com as teses sobre Begriff der Geschichte. E entre o início e a conclusão estão reflexões pertinentes à abordagem de "Untergang des Subjekts" (ADORNO 2011: 241) e de Massenproduktion em geral e na arte: Erfahrung, Phantasievorstellung, Potenz, Erinnern, Gedächtnis, Erzählen, Lyrik e Aura. $^{3}$

Sendo assim, é necessário investigar em seu longo processo de elaboração teórica - sem finalidade sistemática, como costuma ser observado, mas constante e consistente - a passagem de Verfall e Verkümmerung a Katastrophe através de quatro ensaios sobre Sprache (de 1916 a 1933), dos principais escritos pertinentes a Untergang des Subjekts e Massenproduktion (anos 1930) e das reflexões sobre a História (1940).

Os quatro ensaios sobre Sprache são "Über Sprache überhaupt und über die Sprache des Menschen”, "Die Aufgabe des Übersetzers", "Lehre vom Ähnlichen” e "Über das mimetische Vermögen”. Os escritos sobre Untergang des Subjekts e Massenproduktion são fragmentos de Passagen-Werk, "Der Erzähler", Charles Baudelaire. Ein Lyriker im Zeitalter des Hochkapitalismus, "Das Kunstwerk im Zeitalter seiner technischen Reproduzierbarkeit" e "Kleine Geschichte der Photographie". E as reflexões sobre a História são as teses de "Über den Begriff der Geschichte". ${ }^{4}$

\footnotetext{
${ }^{2}$ Com o objetivo de examinar os escritos de Benjamin em seus próprios termos e formulações, utilizamos a edição alemã em sete volumes. Todas as referências e citações remetem essa edição, indicando o volume na data. (Cf. Gesammelte Schriften. Frankfurt am Main: Suhrkamp, 1991, v. VII.).

${ }^{3}$ A hipótese desse artigo - que diz respeito ao enfoque da modernidade - mira o movimento geral do pensamento e de uma série de conceitos e noções benjaminianos, mas é importante fazer referência a dois volumes que abordam os conceitos isoladamente. (Cf. WIZISLA \& OPITZ 2000).

${ }^{4}$ As traduções brasileiras a que recorremos desses escritos estão nas seguintes edições: Escritos sobre mito e linguagem (2013); Ensaios reunidos: escritos sobre Goethe (2009); Origem do drama barroco alemão (1984); Magia e técnica, arte e política (2012); Passagens (2009); Charles Baudelaire: um lírico no auge do capitalismo (1989); Textos escolhidos (1975); Benjamin e a obra de arte (2012). Em caso de necessidade, tendo em vista a dificuldade que pode gerar o propósito de aqui examinar termos e formulações no original, recomendamos o recurso a essas mesmas edições, uma vez que elas ampliam as possibilidades de interlocução - confira as referências bibliográficas. Além disso, pela abordagem em conjunto desses escritos, vale assinalar que Benjamin, de fato, como já se sabe, não era um pensador sistemático; entretanto,
}

Pandaemonium, São Paulo, v. 25, n. 46, mai.-ago. 2022, p. 233-249 
MACEDO, A. - A modernidade em Walter Benjamin

Cabe, por fim, considerar que, em todo esse processo de elaboração teórica cujo cerne é a passagem de Verfall e Verkümmerung a Katastrophe, Benjamin não deixa de tratar de Hilfsmittel para "Vertiefung der Apperzeption" (BENJAMIN 1991a: 498). Isso porque o autor, ao refletir sobre a então nova arte que é o cinema, identifica essa possibilidade de Vertiefung - comparada à análise de Fehlleistung em Freud; comparável a "die Geschichte gegen den Strich zu bürsten" nas teses - ante "die vordem unbemerkt im breiten Strom des Wahrgenommenen mitschwammen" (BENJAMIN 1991a: 498).

\section{Verfall: junção de termo e modernidade}

O estudo comparado, por um lado, de "Über Sprache überhaupt und über die Sprache des Menschen" e "Die Aufgabe des Übersetzers" e, por outro lado, de "Lehre vom Ähnlichen" e "Über das mimetische Vermögen" permite examinar a passagem do uso de Verfall com conotação meramente teológica - "der Verfall des seligen Sprachgeistes, des adamitischen” (BENJAMIN 1991b: 153) - ao seu uso com conotação moderna - "die wachsende Hinfälligkeit des mimetischen Vermögens" (BENJAMIN 1991b: 211) ou, de modo direto, "Verfall dieses Vermögens" (BENJAMIN 1991b: 211).

Nos dois primeiros ensaios, toda a reflexão de Benjamin não considera distinções entre a modernidade e o passado que a precede, ou seja, numa linha de pensamento que é mais teológica que filosófica, a distinção é entre antes e fora da existência e do tempo (relativo a Deus) e na existência e no tempo (relativo à humanidade). Nesse sentido, o primeiro ensaio foca o contraste entre Sprache divina e Sprache humana, portanto, o autor preocupa-se fundamentalmente com a distinção entre Sprache criadora de Deus e Sprache humana como Medium: "Das Mediale, das ist die Unmittelbarkeit aller geistigen Mitteilung, ist das Grundproblem der Sprachtheorie" (BENJAMIN 1991b: 142). Sendo assim, o substantivo Verfall diz respeito especificamente a essa passagem divino-humano e, vale insistir, não faz nenhuma distinção entre o tempo dos primórdios bíblicos e os tempos modernos. ${ }^{5}$

Em "Die Aufgabe des Übersetzers", a reflexão de Benjamin gira em torno de reine Sprache e, igualmente, não há distinção entre a modernidade e os períodos históricos que a antecedem. Entretanto, os conceitos de Sprache e de Geschichte estão em processo de

isso não significa que termos e formulações não possam ser reelaborados e ganhar precisão através de diferentes usos e contextos.

${ }^{5}$ Ao tratar desse primeiro ensaio, Bröcker afirma que Benjamin faz uma crítica a Kant e observa em nota: "Benjamins Lehrer war der Neukantianer Rickert" (Cf. segundo volume de WiZISLA; OPITZ 2000: 740ss). E essa crítica, vale assinalar novamente, é mais teológica que filosófica e não estabelece distinções entre a modernidade e o passado que a precede.

Pandaemonium, São Paulo, v. 25, n. 46, mai.-ago. 2022, p. 233-249 
MACEDO, A. - A modernidade em Walter Benjamin

reelaboração. Embora as considerações sobre o original e a tradução remetam indistintamente à Bíblia, à tragédia grega e aos escritores modernos, a transformação das línguas - entendida como ir além das fronteiras - em sua relação com a reine Sprache é uma questão central: "Jene reine Sprache, die in fremde gebannt ist, in der eigenen zu erlösen, die im Werk gefangene in der Umdichtung zu befreien, ist die Aufgabe des übersetzers" (BENJAMIN 1991c: 19). E Benjamin sentencia: "Um ihretwillen bricht er morsche Schranken der eigenen Sprache: Luther, Voß, Hölderlin, George haben die Grenzen des Deutschen erweitert” (BENJAMIN 1991c: 19).

Mais de dez anos depois desse segundo ensaio, em "Lehre vom Ähnlichen” e "Über das mimetische Vermögen" - duas versões de um mesmo texto -, Benjamin realiza mudanças significativas em seu pensamento. Primeiramente, como indicam os títulos, entre a primeira e a segunda versão o foco passa dos objetos para os sujeitos. A segunda mudança é que "der historischen Entwicklung dieses mimetischen Vermögens erkennen läßt” (BENJAMIN 1991b: 205). E, diferentemente do segundo ensaio, esse histórico especifica a distinção entre "die Merkwelt des modernen Menschen" e "die der alten Völker oder auch der Primitiven” (BENJAMIN 1991b: 206). Em terceiro lugar, Benjamin considera haver na discussão sobre os conceitos de Ähnlichkeit e Sprache duas questões mais gerais relativas ao sujeito.

A primeira dessas questões diz respeito a Wahrnehmung, pois ao abordar o que denomina "Bereiche der Ähnlichkeit", é necessário pensar sobre "Wahrnehmung von Ähnlichkeiten" (BENJAMIN 1991b: 206). E a segunda questão geral é: "Die Frage ist nur die: ob es sich um ein Absterben des mimetischen Vermögens oder aber vielleicht um eine mit ihm stattgehabte Verwandlung handelt" (BENJAMIN 1991b: 206). Dessa forma, além de o foco passar dos objetos aos sujeitos entre a primeira e a segunda versão do texto - como evidencia a própria mudança de título -, esses trechos citados, provenientes de "Lehre vom Ähnlichen", passaram por uma pequena reformulação em "Über das mimetische Vermögen" que, sutilmente, encaminham as reflexões benjaminianas. O autor repete a dúvida, mas não repete os substantivos "Absterben” e "Verwandlung": "Die Frage ist, ob es sich dabei um den Verfall dieses Vermögens oder aber um dessen Transformierung handelt" (BENJAMIN 1991b: 211).

Nas obras que se encontram entre os dois primeiros e os dois últimos escritos sobre Sprache, essa busca do termo para as reformulações relativas aos processos decorrentes da modernidade é mais significativa em "Die Ruine", de Ursprung des deutschen Trauerspiels. Antes, em Goethes Wahlverwandtschaflen, nas discussões benjaminianas sobre a obra consta: "Bei anderer Gelegenheit hat der Dichter auf das Gefühl der »Bangigkeit«" que "mit dem moralischen Verfall in den Wahlverwandtsdtaften beim Leser sich einfinden soll” (BENJAMIN 1991a: 135). Por outro lado, na obra sobre Trauerspiel Benjamin chega a fazer reflexões sobre Sprachzerstückelung, mas é em "Die Ruine" que ele tece as seguintes considerações:

Pandaemonium, São Paulo, v. 25, n. 46, mai.-ago. 2022, p. 233-249 
MACEDO, A. - A modernidade em Walter Benjamin

Wenn mit dem Trauerspiel die Geschichte in den Schauplatz hineinwandert, so tut sie es als Schrift. Auf dem Antlitz der Natur steht >Geschichte< in der Zeichenschrift der Vergängnis. Die allegorische Physiognomie der Natur-Geschichte, die auf der Bühne durch das Trauerspiel gestellt wird, ist wirklich gegenwärtig als Ruine. Mit ihr hat sinnlich die Geschichte in den Schauplatz sich verzogen. Und zwar prägt, so gestaltet, die Geschichte nicht als Prozeß eines ewigen Lebens, vielmehr als Vorgang unaufhaltsamen Verfalls sich aus. Damit bekennt die Allegorie sich jenseits von Schönheit. Allegorien sind im Reiche der Gedanken was Ruinen im Reiche der Dinge. (BENJAMIN 1991a: 353354).

Como está claro, há também no estudo sobre Trauerspiel o recurso ao termo Verfall e os substantivos Ruine e Ruin ainda dizem respeito a esse processo histórico e moderno de Verfall ${ }^{6}$. Assim, o uso do primeiro termo para caracterizar um processo dos tempos modernos está consolidado nesse conjunto de escritos sobre Sprache - complementado por passagens de Ursprung des deutschen Trauerspiels. E as formulações sobre a modernidade estão em andamento: primeiramente, como passamos a tratar, Verfall fará par com Verkümmerung; posteriormente, através de alegorias do pensamento benjaminiano, Ruin fará par com Katastrophe.

\section{Verkümmerung e Verfall: processos de sujeito e objeto na}

\section{modernidade}

Quatro fragmentos de Passagen-Werk sintetizam os resultados dos encaminhamentos discutidos no tópico anterior e, ao mesmo tempo, são pontos de partida para a abordagem desse segundo tópico. Isso porque os fragmentos condensam lapidarmente o aprofundamento dos estudos de Walter Benjamin sobre "den Verfall dieses Vermögens" na modernidade, que sai do âmbito de "das mimetische Vermögen" (BENJAMIN 1991b: 211) e se estende ao sujeito como um todo, detalhando aquilo que é denominado como "Vorgang unaufhaltsamen Verfalls" (BENJAMIN 1991a: 353-354).

No primeiro desses fragmentos, Benjamin especifica seu enfoque geral do processo de Verkümmerung ocorrido na modernidade devido ao modo de produção: "Der Prozeß der

\footnotetext{
${ }^{6}$ A subsequente citação de Borinski, com o termo mais geral Ruin, reforça a formulação de Benjamin: "”Der gebrochene Giebel, die zertrümmerten Säulen Süllen das Wunder bezeugen, daß das heilige Bauwerk selbst den elementarsten Kräften der Zerstörung, Blitz, Erdbeben, standgehalten. Das künstlich Ruinöse dabei erscheint als das letzte Erbe des nur noch tatsächlich, als malerisches Trümmerfeld, auf modernem Boden angesehenen Altertums.«" (BENJAMIN 1991a: 354). Por outro lado, para não haver dúvida, cabe observar que o recurso, por exemplo, ao conceito leibniziano de mônada evidencia que Benjamin já concebe nesse ensaio o sujeito em termos filosóficos modernos.
} 
MACEDO, A. - A modernidade em Walter Benjamin

Verkümmerung der Erfahrung beginnt bereits in der Manufaktur. Er fällt, anders gesprochen, in seinen Anfängen zusammen mit den Anfängen der Warenproduktion.” (BENJAMIN 1991d: 966). ${ }^{7}$

No segundo fragmento, o autor cita um trecho-chave de texto próprio para registrar uma reflexão. A citação volta a focar consequências do processo de modernização: "Wie der industrielle Arbeitsprozeß sich gegen das Handwerk absetzt", também "setzt sich die diesem Arbeitsprozeß entsprechende Form der Mitteilung - die Information - gegen die dem handwerklichen Arbeitsprozeß entsprechende Form der Mitteilung ab, welches die Erzählung ist." (BENJAMIN 1991d: 966). A reflexão assinala que "Sprengkraft [...] in der Information gebunden lag. In der Sensation wird diese Kraft ausgelöst. Mit ihrwird dem Erdboden gleichgemacht, was der Weisheit, der mündlichen Überlieferung, der epischen Seite der Wahrheit noch ähnlich sieht”. (BENJAMIN 1991d: 966). ${ }^{8}$

Já no terceiro fragmento, Benjamin delineia sucintamente as transformações na produção artística em meados do século XIX: "Die Veränderung bestand darin, daß am Kunstwerk die Warenform, an seinem Publikum die Massenform zum ersten Mal einschneidend zur Geltung kam.” (BENJAMIN 1991d: 424). E completa com as concomitâncias e as consequências disso na lírica de Baudelaire: "Gegen diese Veränderung war die Lyrik [...] besonders empfindlich. Es macht die einmalige Signatur der Fleurs $d u$ mal, daß Baudelaire auf eben diese Veränderung mit einem Gedichtbuch erwiderte." (BENJAMIN 1991d: 424).

Por fim, no quarto fragmento, temos as seguintes considerações dialéticas da relação entre Massenproduktion e Untergang des Subjekts, a qual tange a questão política defensiva que já encaminha a abordagem de Katastrophe em "Über den Begriff der Geschichte" a ser desenvolvida especificamente no próximo tópico desse texto: "Der Verfall der Aura und die - durch die defensive Position im Klassenkampf bedingte - Verkümmerung der Phantasievorstellung von einer bessern Natur sind eines. Damit sind der Verfall der Aura und der Verfall der Potenz am Ende eines.” (BENJAMIN 1991d: 457). Benjamin faz essas considerações depois de recorrer a Goethe: "Die Verse der Seligen Sehnsucht »keine Ferne macht dich schwierig, Kommst geflogen und gebannt« - beschreiben die Erfahrung der Aura.” (BENJAMIN 1991d: 457).

Dessa forma, à modernidade de Klassenkampf, industrielle Arbeitsproze $\beta$, Warenform e Massenform Benjamin associa dialeticamente - dando prosseguimento às discussões sobre mimetische Vermögen e Wahrnehmung - Verfall e Verkümmerung de Erfahrung, Phantasievorstellung, Potenz, Erinnern, Gedächtnis, Erzählen, Lyrik e Aura. É esse movimento

\footnotetext{
${ }^{7}$ A referência bibliográfica indica: "(vgl Marx: Das Kapital (I) ed Korsch (Berlin 1932) P 336)” (BENJAMIN 1991d: 966).

${ }^{8}$ A referência bibliográfica indica: “(vgl (Walter Benjamin:) Der Erzähler (Orient und Occident, Neue Folge, Heft 3, Oktober 1936) p 21 Abs 3 - P 22 Abs I Zeile 3; p 22 Abs 3 Zeile I - Ende des Valery-Zitats)" (BENJAMIN 1991d: 966).
}

Pandaemonium, São Paulo, v. 25, n. 46, mai.-ago. 2022, p. 233-249 
MACEDO, A. - A modernidade em Walter Benjamin

apreendido condensadamente nos fragmentos citados que o autor coloca no centro de uma série de ensaios nos quais configura-se uma maneira singular de pensar os efeitos do avanço do capital e da técnica - com a continuidade de Herrschaft - sobre capacidades humanas nos tempos modernos.

Em "Der Erzähler", assim como procedeu ao fazer reflexões que tinham Sprache como foco inicial, Benjamin apreende outros processos de Verfall ligados a Vermögen, uma vez que duas das afirmações mais marcantes recorrem ao segundo termo. Na primeira, o autor refere-se a Erzählen ("Erfahrungen auszutauschen”): "Es ist, als wenn ein Vermögen, das uns unveräußerlich schien, das Gesichertste unter dem Sicheren, von uns genommen würde." (BENJAMIN 1991b: 439). Na segunda afirmação, lemos: "Das Gedächtnis ist das epische Vermögen vor allen anderen.” (BENJAMIN 1991b: 453). Sendo assim, o encadeamento de noções e conceitos classificam Gedächtnis e Erzählen como Vermögen, e essas formulações preparam o próximo passo daquilo que podemos denominar como teoria benjaminiana do sujeito moderno.

Como se sabe, o subtítulo e diversos exemplos de "Der Erzähler" remetem a um escritor do século XIX - "Betrachtungen zum Werk Nikolai Lesskows" -, mas da mesma maneira que reflexões sobre Sprache e Ähnlichkeit conduziram às questões centrais de Vermögen e Wahrnehmung, as considerações sobre Erzählen e Gedächtnis como Vermögen levam a outra questão central: Erfahrung. E o conjunto dessas questões converge para um dos problemas gerais da modernidade intensificado com os acontecimentos do século XX e indicado pela formulação adorniana de Untergang des Subjekts.

O processo de "Verkümmerung der Erfahrung" mencionado no primeiro fragmento aqui citado anteriormente, que já vinha de séculos anteriores devido às transformações no modo de produção, ganha força com fatos que estiveram na ordem do dia durante a vida de Benjamin: "Denn nie sind Erfahrungen gründlicher Lügen gestraft worden als die strategischen durch den Stellungskrieg, die wirtschaftlichen durch die Inflation, die körperlichen durch die Materialschlacht, die sittlichen durch die Machthaber.” (BENJAMIN 1991b: 439). Nesse sentido, é possível dizer que o processo mais geral de Untergang des Subjekts começa a ficar mais nítido no pensamento benjaminiano: "in einem Kraftfeld zerstörender Ströme und Explosionen, der winzige, gebrechliche Menschenkörper” (BENJAMIN 1991b: 439).

Nesse ponto, vale chamar a atenção para os substantivos que Benjamin utiliza para se referir ao processo sofrido pelo sujeito com seu "winzige, gebrechliche Menschenkörper" (BENJAMIN 1991b: 439). Ao contrapor Information e Erzählung no segundo fragmento mencionado aqui anteriormente, o autor recorre ao substantivo Sprengkraft para caracterizar a primeira forma de comunicação. E como está aqui logo no parágrafo anterior, temos o substantivo Explosion para o processo de Verkümmerung der Erfahrung. Trata-se, portanto, de duas palavras 
MACEDO, A. - A modernidade em Walter Benjamin

que remetem a guerra. E sobre a Primeira Guerra Mundial Benjamin diz logo no início de "Der Erzähler": com ela "begann ein Vorgang offenkundig zu werden, der seither nicht zum Stillstand gekommen ist. Hatte man nicht bei Kriegsende bemerkt, daß die Leute verstummt aus dem Felde kamen? nicht reicher - ärmer an mitteilbarer Erfahrung." (BENJAMIN 1991b: 439). Tudo isso permite inferir que as consequências dessa guerra - um acontecimento do século XX - levaram Benjamin a reformular seu pensamento e seus termos, pois os usos dos termos Erlebnis, Chock e Stillstand eram puramente acidentais nesse ensaio ${ }^{9}$. Ao voltar-se, primeiramente, para o século XIX e a lírica de Baudelaire (Erlebnis, Chock) e, posteriormente, em meio a uma nova guerra, para o século XX e o conceito de história (Stillstand), os termos serão precisados.

É nessa linha que, dando um sentido geral para os fragmentos citados no início desse tópico e aprofundando-os através de novos elementos - cidade, multidão, flâneurs, passagens etc. -, podemos ler o conjunto dos ensaios e fragmentos sobre Baudelaire. Nesse sentido, uma das formulações mais marcantes de Benjamin quanto a Untergang des Subjekts é: "Dem Chockerlebnis, das der Passant in der Menge hat, entspridtt das `Erlebnis` des Arbeiters an der Maschinerie.” (BENJAMIN 1991a: 632). Chockerlebnis torna-se norma e essa norma perpassa, na modernidade, Verfall e Verkümmerung de Vermögen, Wahrnehmung, Erfahrung, Phantasievorstellung, Potenz, Erinnern, Gedächtnis, Erzählen; perpassa também, em mais um passo da Fragestellung benjaminiana, a Lyrik baudelairiana - assim como aquela de Poe e Valéry; e como veremos adiante, a arte em geral. Cabe aqui citar um denso trecho - apesar de longo para uma citação e já muito conhecido - de "Über einige Motive bei Baudelaire":

Die Frage meldet sich an, wie lyrische Dichtung in einer Erfahrung fundiert sein könnte, der das Chockerlebnis zur Norm geworden ist. Eine solche Dichtung müßte ein hohes $\mathrm{Ma} ß$ von Bewußtheit erwarten lassen; sie würde die Vorstellung eines Plans wachrufen, der bei ihrer Ausarbeitung im Werke war. Das trifft auf die Dichtung von Baudelaire durchaus zu. Es verbindet ihn, unter seinen Vorgängern, mit Poe; unter seinen Nachfolgern wieder mit Valery. [...]

Je größer der Anteil des Chockmoments an den einzelnen Eindrucken ist, je unablässiger das Bewußtsein im Interesse des Reizschutzes auf dem Plan sein muß, je größer der Erfolg ist, mit dem es operiert, desto weniger gehen sie in die Erfahrung ein; desto eher erfüllen sie den Begriff des Erlebnisses (BENJAMIN 1991a: 615-616).

Sendo assim, a questão central liga-se a Bewußtsein e Bewußtheit diante da multiplicidade moderna, pois se esforçam para contrapor Chockabwehr a Chockerlebnis - essa é a formulação benjaminiana, em seus termos, após um recurso a Freud. ${ }^{10}$ A esse processo Benjamin acrescenta,

\footnotetext{
${ }^{9}$ O uso do termo Chock: "[...] der tiefste Chock jeder individuellen, der Tod [...]" (BENJAMIN 1991b: 457). Por sua vez, o termo Erlebnis aparecia em uma citação de Lukács, proveniente de Theorie des Romans: "Zeiterlebnisse: die Hoffnung und die Erinnerung" (BENJAMIN 1991b: 454).

${ }^{10}$ Tanto as relações com Proust (mémoire involontaire) quanto as referências bibliográficas indicam, especificamente nesse ensaio, apenas uma obra do médico vienense: "Sigm[und] Freud: Jenseits des Lustprinzips. 3. Aufl., Wien 1923".
} 
MACEDO, A. - A modernidade em Walter Benjamin

como registram os fragmentos citados no início desse tópico, mais elementos para a mesma discussão: Verfall der Aura, do lado dos objetos, e Verkümmerung der Phantasievorstellung e Verfall der Potenz, do lado dos sujeitos. Nos escritos sobre Baudelaire, o conceito de aura é abordado brevemente após uma citação que remete o leitor à versão em francês do ensaio do próprio Benjamin que o discute: "Begriff der Aura, der die »einmalige Erscheinung einer Ferne« in ihr begreift.” (BENJAMIN 1991a: 647). Verkümmerung der Phantasievorstellung, consequência dos momentos de Chockerlebnis através do excesso de Bewußtheit e pletora de Erinnerung, por sua vez, tem aqui a seguinte formulação: "Die ständige Bereitschaft der willentlichen, diskursiven Erinnerung, die von der Reproduktionstechnik begünstigt wird, beschneidet den Spielraum der Phantasie.” ( BENJAMIN 1991a: 645). Em seguida, Benjamin explicita a dialética de Verfall der Potenz e Verfall der Aura, também consequência da pletora ante Vermögen e Wahrnehmung do sujeito, através do processo de Bewußtheit de Baudelaire no interior de sua lírica:

Das geschah in der Gestalt einer Chiffre; sie findet sich an fast allen Stellen der »Fleurs du mal«, wo der Blick aus dem menschlichen Auge auftaucht. (Daß Baudelaire sie nicht planmäßig eingesetzt hat, ist selbstverständlich.) Es handelt sich darum, daß die Erwartung, die dem Blick des Menschen entgegendrängt, leer ausgeht. Baudelaire beschreibt Augen, von denen man sagen möchte, daß ihnen das Vermögen zu blicken verloren gegangen ist. In dieser Eigenschaft aber sind sie mit einem Reiz begabt, aus dem der Haushalt seiner Triebe zu einem großen, vielleicht überwiegenden Teile bestritten wird. Im Banne dieser Augen hat sich der Sexus in Baudelaire vom Eros losgesagt. (BENJAMIN 1991a: 648).

Evidente nessas passagens de Ein Lyriker im Zeitalter des Hochkapitalismus, a constante reconsideração de Vermögen e Wahrnehmung, iniciada nos ensaios sobre Sprache, vem acompanhada de uma reconsideração geral dos desdobramentos da modernidade. E o objetivo de Benjamin é estender essa reconsideração ao século XX. Nesse sentido, a observação inicial de "Das Kunstwerk im Zeitalter seiner technischen Reproduzierbarkeit"11 sobre Marx vale também para Baudelaire: "Als Marx die Analyse der kapitalistischen Produktionsweise unternahm, war diese Produktionsweise in den Anfängen." (BENJAmin 1991a: 473). As reflexões sobre Chockerlebnis, que partiram de acontecimentos do século XX - como registra "Der Erzähler" -, retornam a esse século e Benjamin a faz convergir com todas as questões aqui anteriormente abordadas, ou seja, faz convergir Verkümmerung (do sujeito) e Verfall (do objeto) na discussão sobre Aura: "was im Zeitalter der technischen Reproduzierbarkeit des Kunstwerks verkümmert" (BENJAMIN 1991a: 477). E o autor generaliza: "Der Vorgang ist symptomatisch; seine Bedeutung weist über den Bereich der Kunst hinaus" (BENJAMIN 1991a: 477). Em seguida, foca Massenproduktion: "Indem sie die Reproduktion vervielfältigt, setzt sie an die Stelle seines einmaligen Vorkommens sein massenweises.” (BENJAMIN 1991a: 477). E, por fim, assinala

\footnotetext{
11 Todas as referências a seguir são provenientes da Dritte Fassung, por ser a última, mas recorremos a todas as quatro versões do ensaio durante a elaboração desse artigo.
}

Pandaemonium, São Paulo, v. 25, n. 46, mai.-ąo. 2022, p. 233-249 
MACEDO, A. - A modernidade em Walter Benjamin

também as condições de Untergang des Subjekts: "Und indem sie der Reproduktion erlaubt, dem Aufnehmenden in seiner jeweiligen Situation entgegenzukommen, aktualisiert sie das Reproduzierte." (BENJAMIN 1991a: 477).

Nessa altura, cabe chamar a atenção para a recorrência das palavras alemãs que utilizamos no título desse tópico e dizer que, ao aprofundar sobre processos concomitantes, apesar de intercambiáveis, Benjamin consagrou dois usos para se referir, respectivamente, aos processos nos sujeitos e àqueles nos objetos: Verkümmerung der Erfahrung e Verfall der Aura. Dito isso, é oportuno aqui citar um denso parágrafo - apesar de, novamente, longo para uma citação e já muito conhecido - de "Das Kunstwerk im Zeitalter seiner technischen Reproduzierbarkeit":

Es empfiehlt sich, den oben für geschichtliche Gegenstände vorgeschlagenen Begriff der Aura an dem Begriff einer Aura von natürlichen Gegenständen zu illustrieren. Diese letztere definieren wir als einmalige Erscheinung einer Ferne, so nah sie sein mag. An einem Sommernachmittag ruhend einem Gebirgszug am Horizont oder einem Zweig folgen, der seinen Schatten auf den Ruhenden wirft - das heißt die Aura dieser Berge, dieses Zweiges atmen. An der Hand dieser Beschreibung ist es ein Leichtes, die gesellschaftliche Bedingtheit des gegenwärtigen Verfalls der Aura einzusehen. Er beruht auf zwei Umständen, die beide mit der zunehmenden Bedeutung der Massen im heutigen Leben zusammenhängen. Nämlich: Die Dinge sich räumlich und menschlich »näherzubringen " ist ein genau so leidenschaflliches Anliegen der gegenwärtigen Massen wie es ihre Tendenz einer Überwindung des Einmaligen jeder Gegebenheit durch die Aufnahme von deren Reproduktion ist. Tagtäglich macht sich unabweisbarer das Bedürfnis geltend, des Gegenstands aus nächster Nähe im Bild, vielmehr im Abbild, in der Reproduktion, habhaft zu werden. Und unverkennbar unterscheidet sich die Reproduktion, wie illustrierte Zeitung und Wochenschau sie in Bereitschaft halten, vom Bilde. Einmaligkeit und Dauer sind in diesem so eng verschränkt wie Flüchtigkeit und Wiederholbarkeit in jener. Die Entschälung des Gegenstandes aus seiner Hülle, die Zertrümmerung der Aura, ist die Signatur einer Wahrnehmung, deren »Sinn für das Gleichartige in der Welt « so gewachsen ist, daß sie es mittels der Reproduktion auch dem Einmaligen abgewinnt. So bekundet sich im anschaulichen Bereich was sich im Bereich der Theorie als die zunehmende Bedeutung der Statistik bemerkbar macht. Die Ausrichtung der Realität auf die Massen und der Massen auf sie ist ein Vorgang von unbegrenzter Tragweite sowohl für das Denken wie für die Anschauung. (BENJAMIN 1991a: 479-480).

Retornaremos a essas reflexões nas considerações finais. Por ora, assinalamos que, além de uma ampla explicação sobre a maneira de apreender o processo de Verfall der Aura, esse parágrafo torna-se ainda mais importante quando verificamos que ele retoma, pela última vez, um mesmo trecho que se encontra em "Kleine Geschichte der Photographie", ensaio de 1931, e inclui a definição citada em "Der Erzähler": "einmalige Erscheinung einer Ferne”. Em outras palavras, como o autor formula sintética e precisamente no ensaio sobre a fotografia, trata-se de "ein sonderbares Gespinst von Raum und Zeit" (BENJAMIN 1991b: 378). Os termos para as modernas condições de Wahrnehmung no espaço-tempo são Nähe, Flüchtigkeit e Wiederholbarkeit. E Benjamin procura esclarecer como chegou a eles na sétima nota de "Das Kunstwerk im Zeitalter seiner technischen Reproduzierbarkeit”:

Pandaemonium, São Paulo, v. 25, n. 46, mai.-ago. 2022, p. 233-249 
MACEDO, A. - A modernidade em Walter Benjamin

Die Definition der Aura als »einmalige Erscheinung einer Ferne, so nah sie sein mag«, stellt nichts anderes dar als die Formulierung des Kultwerts des Kunstwerks in Kategorien der raum-zeitlichen Wahrnehmung. Ferne ist das Gegenteil von Nähe. Das wesentlich Ferne ist das Unnahbare. In der Tat ist Unnahbarkeit eine Hauptqualität des Kultbildes. Es bleibt seiner Natur nach »Ferne so nah es sein mag «. Die Nähe, die man seiner Materie abzugewinnen vermag, tut der Ferne nicht Abbruch, die es nach seiner Erscheinung bewahrt. (BENJAMIN 1991a: 480).

Dessa forma, questionando a estética tradicional, tornam-se claros os elementos para refletir sobre as transformações relativas à produção e recepção da obra de arte no século XX, as quais, para repetir o título desse tópico, inserem-se dialeticamente nos processos gerais de Verkümmerung e Verfall: Untergang des Subjekts e Massenproduktion. Até aqui, entretanto, apesar de todo o amplo processo de definhamento de capacidades humanas, e como demonstra a clareza dessa última nota citada, os termos da crítica benjaminiana da modernidade ainda estão distantes daqueles de Katastrophe em "Über den Begriff der Geschichte". Além disso, há todo um esforço para discernir e valorizar aspectos positivos, progressistas e revolucionários no cinema - a então nova arte, com novas técnicas.

A despeito de prevalecer na reflexão o foco em "beweglichen Bilder" na relação com "Chockwirkung des Films" (BENJAMIN 1991a: 503), depois de recorrer mais uma vez a Freud, dessa vez sobre Fehlleistung em Psychopathologie des Alltagslebens, Benjamin considera que certas técnicas do cinema - proporcionadas por Hilfsmittel da câmera - possibilitam ao sujeito "Vertiefung der Apperzeption", pois ele depara-se com “die vordem unbemerkt im breiten Strom des Wahrgenommenen mitschwammen" (BENJAMIN 1991a: 498). Esse uso do substantivo Apperzeption - em vez Wahrnehmung - por oposição a "Strom des Wahrgenommenen" reafirma a Vertiefung similiar ao trabalho do psicanalista. E o conjunto da formulação é comparável - em meio a Sturm e Katastrophe - a "die Geschichte gegen den Strich zu bürsten” (BENJAMIN 1991a: 697), que nesse ensaio sobre a obra de arte surgia na parte final como contrapor "der Politisierung der Kunst” a "der Ästhetisierung der Politik” (BENJAMIN 1991a: 508).

\section{Katastrophe: passado e modernidade, futuro-ruína a frear}

Como fizemos no tópico anterior para apreender o andamento das formulações benjaminianas, partimos aqui de outros seis fragmentos de Passagen-Werk. Eles mostram que, novamente, o autor se vale de acontecimentos do século XX - especialmente a catástrofe maior que é uma guerra em escala mundial - para refletir sobre o século XIX. Nesse sentido, os fragmentos, mais uma vez, condensam lapidarmente considerações a partir de Blanqui, Baudelaire e Strindberg. A partir do primeiro: "Contrepartie der Blanqui'schen Weltansicht: das Universum ist eine Stätte dauernder Katastrophen.” (BENJAMIN 1991d: 168). A partir de Baudelaire: "Der spleen ist das

Pandaemonium, São Paulo, v. 25, n. 46, mai.-ago. 2022, p. 233-249 
MACEDO, A. - A modernidade em Walter Benjamin

Gefühl, das der Katastrophe in Permanenz entspricht." (BENJAMIN 1991d: 438). E a partir de Strindberg (“die Hölle ist nichts, was uns bevorstünde - sondern dieses Leben hier)": "Der Begriff des Fortschritts ist in der Idee der Katastrophe zu fundieren. Daß es »so weiter « geht, ist die Katastrophe. Sie ist nicht das jeweils Bevorstehende sondern das jeweils Gegebene." (BENJAMIN 1991d: 592).

Dessa forma, Benjamin refletia pessimistamente sobre o estado catastrófico da modernidade e sentimentos diante desse estado. Voltando ao século $\mathrm{XX}$, o registro de uma afirmação de Adorno evidencia que ele fornecia ao autor de "Über den Begriff der Geschichte" mais um termo-chave para suas formulações: “»Das Jüngstvergangene stellt allemal sich dar als sei es durch Katastrophen vernichtet worden.« Wiesengrund, brieflich (5.6.1935)” (BENJAMIN 1991d: 501). E Benjamin, em outros três fragmentos, define Katastrophe à sua maneira e examina a relação dela com o passado (Überlieferung) e o futuro (Ruin). As definições de "historischer Grundbegriffe" exageram o habitual laconismo: "Die Katastrophe - die Gelegenheit verpaßt haben; der kritische Augenblick - der status quo droht erhalten zu bleiben; der Fortschritt - die erste revolutionäre Maßnahme.” (BENJAMIN 1991d: 593). Em relação ao passado, Benjamin indaga - "Wovor werden die Phänomene gerettet?" - e responde: "Nicht nur, und nicht sowohl vor dem Verruf und der Mißachtung in die sie geraten sind als vor der Katastrophe wie eine bestimmte Art ihrer Überlieferung, ihre »Würdigung als Erbe« sie sehr oft darstellt.” (BENJAMIN 1991d: 591). Depois conclui: “- Sie werden durch die Aufweisung des Sprungs in ihnen gerettet. - Es gibt eine Überlieferung, die Katastrophe ist." (BENJAMIN 1991d: 591). Por fim, em relação ao futuro: "Das Ideal des chockförmigen Erlebnisses ist die Katastrophe." (BENJAMIN 1991d: 642). E Benjamin exemplifica: "Das wird im Spiel sehr deutlich: durch immer größere Misen, die das Verlorene retten sollen, steuert der Spieler auf den absoluten Ruin zu.” (BENJAMIN 1991d: 642).

Assim como nesses fragmentos, em "Über den Begriff der Geschichte" as reflexões de Benjamin dizem respeito a todo o passado, ou seja, não se limitam à modernidade. Entretanto, como examinamos nos tópicos anteriores, depois da junção do termo Verfall e modernidade, o autor foca nessa modernidade os processos de Verkümmerung e Verfall como ligados às questões gerais de Untergang des Subjekts e Massenproduktion. Desse maneira, trata-se de um passado reconsiderado a partir de um agora - Jetztzeit - que é, obviamente, um momento moderno visto que do então presente.

Dito isso, cabe assinalar que as complexas condensações dos fragmentos citados ganham variações e aprofundamento na clareza das teses em "Über den Begriff der Geschichte". Se em "Über Sprache überhaupt und über die Sprache des Menschen" o pensamento era mais teológico que filosófico, aqui se concluem as reelaborações em que o filosófico - uma linha própria de dialética materialista - passa a prevalecer. E Benjamin procede à sua mescla singular de 
MACEDO, A. - A modernidade em Walter Benjamin

conceitos-chave de origem marxista e teológica para sintetizar em sua nona tese, que é necessário citar - apesar de, mais uma vez, longa para uma citação e já muito conhecida:

Es gibt ein Bild von Klee, das Angelus Novus heißt. Ein Engel ist darauf dargestellt, der aussieht, als wäre er im Begriff, sich von etwas zu entfernen, worauf er starrt. Seine Augen sind aufgerissen, sein Mund steht offen und seine Flügel sind ausgespannt. Der Engel der Geschichte muß so aussehen. Er hat das Antlitz der Vergangenheit zugewendet. Wo eine Kette von Begebenheiten vor uns erscheint, da sieht er eine einzige Katastrophe, die unablässig Trümmer auf Trümmer häuft und sie ihm vor die Füße schleudert. Er möchte wohl verweilen, die Toten wecken und das Zerschlagene zusammenfügen. Aber ein Sturm weht vom Paradiese her, der sich in seinen Flügeln verfangen hat und so stark ist, daß der Engel sie nicht mehr schließen kann. Dieser Sturm treibt ihn unaufhaltsam in die Zukunft, der er den Rücken kehrt, während der Trümmerhaufen vor ihm zum Himmel wächst. Das, was wir den Fortschritt nennen, ist dieser Sturm. (BENJAMIN 1991a: 697698).

Conforme surgia laconicamente nos fragmentos e aqui é articulado com clareza imagética, Benjamin questiona o conceito de Fortschritt - que, em larga medida, permaneceu inquestionável em Marx e na atuação de marxistas - ao colocá-lo como aquilo que, comparável a Sturm, produz "Trümmer auf Trümmer", ou seja, Katastrophe. Assim, pensando na perspectiva da Tradition der Unterdrückten, o que é realmente Katastrophe é conformar-se com a vigência permanente de Ausnahmezustand, ou seja, "die Gelegenheit verpaßt haben" (BENJAMIN 1991a: 697). E Fortschritt real, nessa mesma perspectiva, é "die erste revolutionäre Maßnahme." (BENJAMIN 1991d: 593). Em outras palavras, a atuação deve ter como Aufgabe a descontinuidade - não a continuidade - que é "die Herbeiführung des wirklichen Ausnahmezustands" (BENJAMIN 1991a: 697).

Isso fica mais claro quando compreendemos o processo de elaboração da abordagem benjaminiana. Como se sabe, ela se constrói a partir de reflexões sobre a convergência entre uma metáfora de Marx e a concepção de Fortschritt da social-democracia alemã. A metáfora de Marx diz que "die Revolutionen sind die Lokomotive der Weltgeschichte." (BENJAMIN 1991a: 1232). E Benjamin questiona em documentos de seu arquivo: "Vielleicht sind die Revolutionen der Griff des in diesem Zuge reisenden Menschengeschlechts nach der Notbremse.” (BENJAMIN 1991a: 1232). Nesse sentido, é preciso fazer a crítica da analogia que possibilita a aproximação entre metáfora e "sozialdemokratische Theorie" (BENJAMIN 1991a: 701), ou seja, a analogia entre trilho e tempo. É ela que fundamenta, ao mesmo tempo, os conceitos de Fortschritt e Geschichte: "Die Vorstellung eines Fortschritts des Menschengeschlechts in der Geschichte ist von der Vorstellung ihres eine homogene und leere Zeit durchlaufenden Fortgangs nicht abzulösen.” (BENJAMIN 1991a: 701).

Sendo assim, o alvo principal da crítica é certo Fortgang e social-democracia, mas ela atinge certa concepção de Revolution e Marx, pois, para a analogia de Benjamin, se o tempo continuar sendo concebido como "homogene und leere", ele simplesmente possibilitará, também 
MACEDO, A. - A modernidade em Walter Benjamin

no futuro, "Katastrophe in Permanenz" (BENJAMIN 1991d: 438), e não conduzirá - de maneira mecânica como o avanço de um trem sobre o trilho - a revoluções. Como registra o fragmento de Passagen-Werk, esse tempo aproxima-se daquele do "Ideal des chockförmigen Erlebnisses" que “steuert der Spieler auf den absoluten Ruin zu" (BENJAMIN 1991d: 642). Portanto, o que se coloca como emergência é frear a locomotiva, certamente para redefinir a direção, ou seja, o destino de Unterdrückten e, de maneira geral, de Menschengeschlecht. ${ }^{12}$

\section{Considerações finais}

Cabe, enfim, para iniciar as considerações finais, indagar: como fazer essa interrupção, ou seja, evitar a ruína? Ou ainda, para usar a formulação adorniana, como conseguir "die Rettung des Menschen"? (ADORNO 2011: 241). Em suma, como brecar a marcha permanente da modernidade na direção equivocada de Katastrophe? O ponto-chave da resposta, em "Über den Begriff der Geschichte", é rever a forma de apreender os acontecimentos do passado para reconsiderar a forma de agir no presente e no futuro.

É célebre a afirmação de Benjamin sobre a relação, primeiramente, entre Kultur e Barbarei: "Es ist niemals ein Dokument der Kultur, ohne zugleich ein solches der Barbarei zu sein.” (BENJAMIN 1991a: 696). E, em seguida, sobre Überlieferung e Barbarei: "Und wie es selbst nicht frei ist von Barbarei, so ist es auch der Prozeß der Überlieferung nicht, in der es von dem einen an den andern gefallen ist." (BENJAMIN 1991a: 696). Diante disso, ao voltar-se para a investigação do passado, o historiador de qualquer área - como faz Benjamin, por exemplo, ao dedicar-se a diversos aspectos da sociedade parisiense do século XIX - deve contrapor-se a esse processo, que é a própria continuidade da catástrofe - "Es gibt eine Überlieferung, die Katastrophe ist" (BENJAMIN 1991d: 591). Isso significa evitar "sich zum Werkzeug der herrschenden Klasse herzugeben" (BENJAMIN 1991a: 695) e, em outra formulação célebre, contrapor-se à mecânica histórica de Herrschaft: "Der historische Materialist rückt daher nach

\footnotetext{
${ }^{12}$ Conforme definimos na introdução e nas notas iniciais, o objetivo desse artigo é ater-se aos escritos do próprio Benjamin, recorrendo ao exame, no original, de seus termos e formulações. Entretanto, é uma leitura que realizamos no ano de 2021. Nesse sentido, é oportuno colocar um parênteses nesses termos e formulações para fazer referência, nessa altura, a uma série de estudos que contribuíram para a abordagem desse artigo, pois tratam de questões relacionadas ao enfoque da modernidade como Katastrophe após a morte de Benjamin - mostrando sua persistente atualidade -, desde acontecimentos da Segunda Guerra Mundial e da história latino-americana até as consequências da queda do Berliner Mauer e dos ataques de 11 de setembro de 2001: Löwy (2005), Agamben (2004), Adorno (2003), Arantes (2014), Schwarz (2012, 1999), Gagnebin (2006, 1999), Bolle (2000), Konder (1999), Seligmann-Silva (2003, 2000), Hobsbawm (1995), Kurz (2008). Vale registrar, ainda, que 2021 é o ano em que está em curso uma pandemia disseminada rapidamente por um mundo globalizado, constituindo mais um momento de intensificação dessa modernidade como Katastrophe.
}

Pandaemonium, São Paulo, v. 25, n. 46, mai.-ago. 2022, p. 233-249 
MACEDO, A. - A modernidade em Walter Benjamin

Maßgabe des Möglichen von ihr ab. Er betrachtet es als seine Aufgabe, die Geschichte gegen den Strich zu bürsten.” (BENJAMIN 1991a: 696-697).

Nessa direção, a proposta de Benjamin tem, como dissemos, proximidade com a discussão sobre Fehlleistung (de Freud) e sobre Hilfsmittel (da câmera), pois coloca o foco da atenção em "die vordem unbemerkt im breiten Strom des Wahrgenommenen mitschwammen" (BENJAMIN 1991a: 498). Questão tanto mais importante quando constatamos que as características da relação entre Reproduktion e Bild - "Einmaligkeit und Dauer sind in diesem so eng verschränkt wie Flüchtigkeit und Wiederholbarkeit in jener.” (BENJAMIN 1991a: 479) atingiria níveis inimagináveis na era online de social media e streaming mundiais. Inimagináveis mas cujo sentido, vale repetir a citação, permanece o mesmo em meio à também inimaginável proporção planetária de Massen e Statistik: "Die Dinge sich räumlich und menschlich »näherzubringen «" é "leidenschaflliches Anliegen der gegenwärtigen Massen" tanto quanto "ihre Tendenz einer Überwindung des Einmaligen jeder Gegebenheit durch die Aufnahme von deren Reproduktion" (BENJAMIN 1991a: 479). Assim, é com a mesma finalidade de atentar a unbemerkt im breiten Strom que o Historicismo é questionado nas teses benjaminianas. É preciso citar - apesar de, mais uma vez, longa para uma citação e já muito conhecida - parte da tese XVII de "Über den Begriff der Geschichte":

Zum Denken gehört nicht nur die Bewegung der Gedanken sondern ebenso ihre Stillstellung. Wo das Denken in einer von Spannungen gesättigten Konstellation plötzlich einhält, da erteilt es derselben einen Chock, durch den es sich als Monade kristallisiert. Der historische Materialist geht an einen geschichtlichen Gegenstand einzig und allein da heran, wo er ihm als Monade entgegentritt. In dieser Struktur erkennt er das Zeichen einer messianischen Stillstellung des Geschehens, anders gesagt, einer revolutionären Chance im Kampfe für die unterdrückte Vergangenheit. (BENJAMIN 1991a: 702-703).

Eis a formulação benjaminiana de Dialektik im Stillstand em terminologia, ao mesmo tempo, filosófica (Monade), teológica (messianischen), política (Kampfe) e marxista (historische Materialist). Como está claro, diferentemente de outros trechos citados, Chock aqui é tomado em sentido oposto àquele de Chockerlebnis. E assim como Freud analisa Fehlleistung em Bewegung de fala de um paciente ou espectadores têm "Vertiefung der Apperzeption" (BENJAMIN 1991a: 498) através de Hilfsmittel da camêra em Bewegung de imagens de um filme, a "materialistische Geschichtsschreibung" realiza Chock em "Bewegung der Gedanken" quando identifica o que Benjamin denomina de "Spannungen gesättigten Konstellation", e disso decorre "Stillstellung des Geschehens" (BENJAMIN 1991a: 702-703). É aí que se configura o equivalente de Fehlleistung ou eingreiffen com Hilfsmittel, ou seja, aquilo que deve ser examinado detidamente. Tiedemann, em livro cujo título é justamente Dialektik im Stillstand, reforça o que já está claro nas formulações benjaminianas: "Durch die Stillstellung der Dialektik wird den geschichtlichen >Siegern` der Vertrag gekündigt und alles Pathos auf die Rettung des Unterdrückten gelegt." (TIEDEMANN 2016: 32).

Pandaemonium, São Paulo, v. 25, n. 46, mai.-ago. 2022, p. 233-249 
MACEDO, A. - A modernidade em Walter Benjamin

Em "Das Kunstwerk im Zeitalter seiner technischen Reproduzierbarkeit”, Benjamin explica a aproximação entre cinema e psicanálise, que consideramos também esclarecer o proceder do método na "materialistische Geschichtsschreibung": "Hier greift die Kamera mit ihren Hilfsmitteln, ihrem Stürzen und Steigen, ihrem Unterbrechen und Isolieren, ihrem Dehnen und Raffen des Ablaufs, ihrem Vergrößern und ihrem Verkleinern ein.” (BENJAMIN 1991a: 500). O resultado disso é: "Vom Optisch-Unbewußten erfahren wir erst durch sie, wie von dem Triebhaft-Unbewußten durch die Psychoanalyse.” (BENJAMIN 1991a: 500). Nesse sentido, essa aproximação permite inferir, em Benjamin, uma proposta de método para investigar e experienciar uma espécie de Unbewußte social da Tradition der Unterdrückten, ou seja, uma proposta para ir contra a corrente da repressão provocada pela "versão oficial da história" (LÖWY 2005: 74). ${ }^{13}$ É isso que justifica a delimitação de certo "geschichtlichen Gegenstand": "einer revolutionären Chance im Kampfe für die unterdrückte Vergangenheit.” (BENJAMIN 1991a: 702703). Como explica Löwy, trata-se de focar "possibilidades inesperadas, que podem produzir o novo", ou seja, "opor uma concepção aberta da história como práxis humana" a "toda doutrina teleológica, confiante nas 'leis da história' ou na acumulação gradual de reformas na via certa e garantida do Progresso infinito" (LÖWY 2005: 136).

Enfim, fiel a seu preceito de den Pessimismus organisieren, o que Benjamin coloca no horizonte é um futuro-ruína e o objetivo é evitá-lo, ou seja, evitar a continuidade daquilo em que se tornou verdadeiramente a modernidade - e permanece, no século XXI, sendo "`noch`möglich" (BENJAMIN 1991a: 697): Katastrophe. Após os processos de Verkümmerung e Verfall, Untergang des Subjekts e Massenproduktion, ocorre aqui a articulação da forma de apreender os acontecimentos do passado e a forma de agir no presente e no futuro: essa articulação configura a proposta benjaminiana de resistência ao estado de Katastrophe, ou seja, investigar e experienciar - em cada Monade kristallisiert -, tendo em vista Vertiefung der Apperzeption, Gelegenheit para acionar Notbremse.

\section{Referências bibliográficas}

ADORNO, Theodor. Kulturkritik und Gesellschaft. Frankfurt am Main: Suhrkamp, 2011.

ADORNO, Theodor. Gesammelte Schriften. Frankfurt am Main: Suhrkamp, 2003, v. XX.

Agamben, Giorgio. Estado de exceção. São Paulo: Boitempo, 2004 (Estado de sítio).

\footnotetext{
13 Löwy dá o exemplo da comemoração do V centenário da descoberta das Américas (1492-1992): "Enquanto a Espanha, a Europa e os Estados Unidos se apressavam em comemorar a chegada de Cristóvão Colombo, uma reunião latino-americana realizada em outubro de $1991 \mathrm{em}$ Xelaju, na Guatemala - um dos bastiões da cultura maia - conclamava para a comemoração de 'Cinco séculos de resistência indígena e popular'." (LÖWY 2005: 82). Outros dois exemplos significativos são Canudos (GALVÃO, 2001) e Menocchio (GINZBURG, 2006).
}

Pandaemonium, São Paulo, v. 25, n. 46, mai.-ago. 2022, p. 233-249 
MACEDO, A. - A modernidade em Walter Benjamin

ARANTES, Paulo. O novo tempo do mundo. São Paulo: Boitempo, 2014.

BENJAMIN, Walter. Gesammelte Schriften, v. 1. Frankfurt am Main: Suhrkamp, 1991a.

BENJAMIN, Walter. Gesammelte Schriften, v. 2. Frankfurt am Main: Suhrkamp, 1991b.

Benjamin, Walter. Gesammelte Schriften, v. 4. Frankfurt am Main: Suhrkamp, 1991c.

BENJAMIn, Walter. Gesammelte Schriften, v. 5. Frankfurt am Main: Suhrkamp, 1991d.

BENJAMIN, Walter. Escritos sobre mito e linguagem. S. Paulo: Duas Cidades; Editora 34, 2013.

Benjamin, Walter. Magia e técnica, arte e política. 8. ed. São Paulo: Brasiliense, 2012.

BENJAMIN, Walter. Benjamin e a obra de arte. Rio de Janeiro: Contraponto, 2012.

Benjamin, Walter. Passagens. Belo Horizonte: Editora UFMG; São Paulo: Imprensa Oficial do Estado de São Paulo, 2009.

BENJAMIN, Walter. Ensaios reunidos: escritos sobre Goethe. São Paulo: Editora 34, 2009.

BENJAMIN, Walter. Charles Baudelaire: um lírico no auge do capitalismo. São Paulo: Brasiliense, 1989.

Benjamin, Walter. Origem do drama barroco alemão. São Paulo: Brasiliense, 1984.

BENJAMIN, Walter. Textos escolhidos. São Paulo: Abril, 1975 (Os pensadores, v. XLVIII).

BolLE, Willi. Fisiognomia da metrópole moderna: representação da história em Walter Benjamin. 2. ed. São Paulo: Edusp, 2000.

GAGNEBIN, Jeanne Marie. Lembrar escrever esquecer. São Paulo: Editora 34, 2006.

Gagnebin, Jeanne Marie. História e narração em Walter Benjamin. São Paulo: Perspectiva, 1999.

Galvão, Walnice Nogueira. O Império do Belo Monte. São Paulo: Perseu Abramo, 2001.

GINZBURG, Carlo. O queijo e os vermes. São Paulo: Companhia das Letras, 2006.

Hobsbawm, Eric. Era dos extremos: o breve século XX. São Paulo: Companhia das Letras, 1995.

KONDER, Leandro. Walter Benjamin: o marxismo da melancolia. 3. ed. Rio de Janeiro: Civilização Brasileira, 1999.

KuRZ, Robert. O colapso da modernização. 3. ed. Rio de Janeiro: Paz e Terra, 2008.

LÖWY, Michael. Walter Benjamin: aviso de incêndio. São Paulo: Boitempo, 2005.

SCHWARZ, Roberto. Martinha versus Lucrécia. São Paulo: Cia. das Letras, 2012.

SCHWARZ, Roberto. Sequências brasileiras. São Paulo: Cia. das Letras, 1999.

SEligmanN-SILVA, Márcio. História, memória, literatura. Campinas: Editora da Unicamp, 2003.

SeligmanN-SILVA, Márcio; NeSTROVSKI, Arthur (orgs.). Catástrofe e representação. São Paulo: Escuta, 2000.

Tiedemann, Rolf. Dialektik im Stillstand. Frankfurt am Main: Suhrkamp, 2016.

WIZISLA, Erdmut; OPITZ, Michael (orgs.). Benjamins Begriffe. Frankfurt am Main: Suhrkamp, 2000, v. II. 